\title{
4. MODERNIDADE E PÓS-MODERNIDADE EM "O ALIENISTA": NOTAS SOBRE A RACIONALIDADE CIENTÍFICA
}

\author{
Jaqueline Mielke Silva ${ }^{1}$ \\ Clarissa Santos Lucena ${ }^{2}$
}

\begin{abstract}
Resumo: A obra "O Alienista" de Machado de Assis questiona o poder das teorias científicas evolucionistas, positivistas e sócio-darwinistas trazidas da Europa no final do século XIX. O positivismo influenciou o Direito Processual Civil na chamada modernidade. Entretanto, o paradigma cientificista é insuficiente para resolver os problemas da pósmodernidade, havendo a necessidade de ser repensado.
\end{abstract}

Palavras-chave: Alienista, cientificismo, processo

\begin{abstract}
The work "The Alienist" by Machado de Assis questions the power of scientific theories evolutionists, positivist and socio-Darwinists brought from Europe in the late nineteenth century. Positivism influenced the Civil Procedural Law in the post modernity. However, the scientific model is insufficient to solve the problems of postmodernity, there is a need to be re-thought.
\end{abstract}

Keywords: Psychiatrist, scientificism, process

\section{O racionalismo científico da modernidade na obra "O Alienista"}

A temática central da obra "O Alienista" conduz a uma eterna reflexão sobre os limites entre a insanidade e a razão, o poder da palavra, a loucura da ciência e as relações estabelecidas na sociedade do período.

Ao utilizar a questão da loucura enquanto questão central, a obra encerra novas possibilidades de estudo, por ser um relato que apresenta ao leitor os rituais de subserviência, bajulação e clientelismo presentes no Brasil em finais do século XIX. Em contrapartida, o texto questiona o poder das teorias científicas evolucionistas, positivistas e sócio-darwinistas trazidas

\footnotetext{
1 Professora dos curso de Pós-Graduação da IMED, IDC, AJURIS e Uniritter, e da disciplina de Direito Processual Civil I, do Cesuca, Doutora em Direito (Unisinos).

2 Professora no Curso de Direito do IPA e na FADERGS, Mestre em Direito (Unisinos). 
da Europa que, neste momento histórico, indicariam as respostas para todos os males desta civilização em busca do progresso.

$\mathrm{O}$ autor penetra na consciência das personagens, sondando-lhes o funcionamento e captando os impulsos contraditórios dos seres humanos, desmascarando o jogo das relações sociais, enfatizando o contraste entre a essência e a aparência, em que o sucesso financeiro é o objetivo primordial. O homem deixa de ser o centro, mas passa a ser parte de um sistema. Há algumas características marcantes no conto, que não podemos deixar passarem despercebidas: apreensão da realidade, o não-eu em nível de realidade e descrição, a precisão de detalhes, ocupando o lugar central enquanto técnica narrativa.

O conto apresenta o grande paradoxo da sociedade brasileira no século XIX. Neste período, a ciência teria estabelecido o primado da razão e do racionalismo na Europa. Essas idéias cientificistas, positivistas, evolucionistas e sócio-darwinistas seriam transplantadas para o Brasil de maneira a coexistirem com as estruturas vigentes. Dessa maneira, as análises sociais presentes no conto, principalmente em relação ao comportamento dos personagens que utilizam a lisonja e a bajulação para alcançarem seus objetivos recriariam o conceito de loucura como uma paródia à ordem desejada. O cientificismo teve reflexos no Direito, consoante será abordado no próximo capítulo.

\section{O Direito e a racionalidade científica da modernidade}

A modernidade ${ }^{3}$, no plano econômico, tem suas origens no advento da máquina a vapor, que impulsionou o capitalismo. No plano das idéias, o iluminismo, difundido a partir do século XVIII, pregava o desenvolvimento moral e material do homem pelo conhecimento. Historicamente, o projeto do iluminismo afirmava a razão e o método científico como as únicas fontes de conhecimento válido, rejeitando qualquer concepção de mundo derivada do dogma, da superstição e da fantasia.

Enquanto proposta emancipatória, o iluminismo estava condicionado à determinação racional dos fins, no debate e na efetivação de valores julgados belos, justos e verdadeiros. $\mathrm{Na}$ medida em que saudava a criatividade humana, a descoberta e a busca da excelência individual

\footnotetext{
${ }^{3}$ Sobre o tema vide: PATTERSON, Dennis. Law \& Truth. New York: Oxford University Press, 1996, p. 151 e ss. 
em nome do progresso, acolhia o turbilhão de mudanças, da transitoriedade e da fragmentação, sem as quais a modernização não se poderia realizar ${ }^{4}$.

Segundo Sérgio ROUANET ${ }^{5}$, a modernidade, tal como foi explicitada por Max WEBER, constitui-se no resultado do processo de racionalização preconizado pelo iluminismo, que redundou em enormes modificações não só na sociedade como também na cultura. Quanto ao homem, com o advento do mundo moderno, ele mesmo foi separado dos outros homens e desmembrado no exercício de três papéis diferentes e, às vezes, até contraditórios: o de cidadão, enquanto membro da sociedade política; o de burguês, enquanto agente econômico; e o de particular, enquanto indivíduo e membro de uma família ${ }^{6}$.

Leonel Severo ROCHA ${ }^{7}$ segue o mesmo entendimento de Max WEBER, posicionando-se no sentido de que a modernidade está atrelada à racionalidade, e que esta racionalidade estaria ligada a uma forte noção de Estado:

Toda a teoria jurídica dominante (...) deriva de um contexto histórico bem preciso, ou seja, é uma teoria que se fundamenta na forma de sociedade que chamamos de modernidade. É uma teoria jurídica da modernidade, e o significado mais lapidar que se pode dar à expressão modernidade seria aquele de um período, de uma fase em que há uma grande crença numa certa idéia de racionalidade, e essa racionalidade, no Direito, estaria ligada a uma forte noção de Estado. Assim, toda teoria jurídica da modernidade é uma teoria ligada à noção de Estado, e essa racionalidade se desenvolveu, principalmente, numa dinâmica que se chama normativismo.

Ao contrário da ciência aristotélica ${ }^{8}$, a ciência moderna desconfia das evidências da nossa experiência imediata. A partir desses pressupostos, o conhecimento científico avança pela observação descomprometida e livre dos fenômenos naturais.

\footnotetext{
${ }^{4}$ Neste sentido: HARVEY, David. Condição pós-moderna. 6. ed. São Paulo: Loyola, 1996, p. 23.

${ }^{5}$ In: ROUANET, Sérgio. As razões do lluminismo. São Paulo: Companhia das Letras, 1998.

${ }^{6}$ In: ROUANET, Sérgio. As razões do lluminismo, p. 240.

${ }^{7}$ In: ROCHA, Leonel Severo. Epistemologia Jurídica. 2. ed. São Leopoldo: EdUNISINOS, 2003, p. 185.

8 "Como bem salienta Einstein no prefácio ao Diálogo sobre os Grandes Sistemas do Mundo, Galileu esforça-se denodadamente por demonstrar que a hipótese dos movimentos de rotação e de translação da terra não é refutada pelo facto de não observarmos quaisquer efeitos mecânicos desses movimentos, ou seja, pelo facto de a Terra nos parecer parada e quieta (Einstein, 1970: xvii). Por outro lado, é total a separação entre a natureza e o ser humano. A natureza é tão-só extensão e movimento; é passiva, eterna e reversível, mecanismo cujos elementos se podem desmontar e depois relacionar sob a forma de leis; não tem qualquer outra qualidade ou dignidade que nos impeça de desvendar os seus mistérios, desvendamento que não é contemplativo, mas antes activo, já que visa conhecer a natureza para a dominar e controlar. Como diz Bacon, a ciência fará da pessoa humana 'o senhor e o possuidor da natureza'”. Boaventura de Sousa Santos (In: A crítica da razão indolente - contra o desperdício da experiência. São Paulo: Cortez, 2000, p. 62).
} 
As idéias que presidem a observação e a experimentação são as idéias claras e simples, a partir das quais se pode ascender a um conhecimento mais profundo e rigoroso da natureza. Trata-se das idéias matemáticas. A matemática forneceu à ciência moderna além de um instrumento privilegiado de análise, mas também a lógica da investigação e, ainda, o modelo de representação da própria estrutura da matéria. Duas conseqüências principais derivam desse lugar da matemática na ciência moderna ${ }^{9}$ :

- Conhecer significa quantificar. O rigor científico afere-se pelo rigor das medições. O que não é quantificável é cientificamente irrelevante.

- O método científico assenta na redução da complexidade. O mundo é complicado, e a mente humana não o pode compreender completamente. Conhecer significa dividir e classificar para depois poder determinar relações sistemáticas entre o que se separou. Uma das regras em René DESCARTES ${ }^{10}$ consiste precisamente em "dividir cada uma das dificuldades ... em tantas parcelas quanto for possível e requerido para melhor as resolver".

Essa idéia de mundo-máquina é tão poderosa que vai transformar-se na grande hipótese universal da época moderna ${ }^{11}$. O determinismo mecanicista é o horizonte certo de uma forma de conhecimento que se pretende utilitário e funcional, reconhecido menos pela capacidade de compreender profundamente o real do que pela capacidade de o dominar e transformar.

No plano social, é esse também o horizonte cognitivo mais adequado aos interesses da burguesia ascendente, que via na sociedade em que começava a dominar, o estágio final da evolução da humanidade (o estado positivo de Comte $^{12}$; a sociedade industrial de Spencer; a solidariedade orgânica de Durkheim $\left.{ }^{13}\right)^{14}$. Assim como foi possível descobrir as leis da natureza, seria igualmente possível descobrir as leis da sociedade ${ }^{15}$.

\footnotetext{
${ }^{9}$ SANTOS, Boaventura de Sousa. A crítica da razão indolente - contra o desperdício da experiência, p. 63.

${ }^{10}$ Ver DESCARTES, René. Discurso do Método e as Paixões da Alma. Lisboa: Sá Costa, 1984, p. 17.

11 Neste sentido, Boaventura de Sousa Santos (In: A crítica da razão indolente - contra o desperdício da experiência, p. 64).

${ }^{12}$ Segundo Jean CARBONNIER (In: Sociologia Jurídica. Coimbra: Almedina, 1979, p. 92), "a atitude de COMTE para com o direito é duplamente sociológica: $1^{\circ}$ ) Pelo método legislativo (as leis devem ser retiradas da experiência, e não de conceitos a priori, ao contrário do que fizeram os legisladores de 1804 , espíritos metafísicos; $2^{\circ}$ ) pelo fundamento da doutrina (é necessário, contra o atomismo do Código de Napoleão, reconhecer a prioridade das realidades colectivas)".

${ }^{13}$ Segundo Jean CARBONNIER (In: Sociologia Jurídica, p. 117), a abertura de Durkheim para o direito "contribuiu fortemente para orientar a sua sociologia, para fazer dela, no fundo, uma sociologia das instituições - das normas, das instituições, dos sistemas - mais do que dos fenómenos e, no que se refere ao método, mais uma sociologia
} 
A forma como o modelo mecanicista foi assumido teve duas conseqüências. A primeira delas - sem qualquer dúvida dominante - consistiu em aplicar, na medida do possível, ao estudo da sociedade, todos os princípios epistemológicos e metodológicos que dominavam o estudo da natureza desde o século XVI. A Segunda - durante muito tempo isolada, mas hoje com cada vez mais adeptos - consistiu em reivindicar para as ciências sociais um estatuto epistemológico e metodológico próprio, com base na especificidade do ser humano e na sua distinção radical em relação à natureza ${ }^{16}$.

O resultado da concepção de modernidade acima explicitado foi que, no seu âmbito, houvesse uma pretensão por parte do Estado na produção de normas jurídicas. O Estado moderno diferencia-se de outros por avocar para si o monopólio na produção do Direito. Segundo João Maurício ADEODATO ${ }^{17}$, nem sempre isto ocorreu desta forma:

$\mathrm{Na}$ antigüidade havia instituições produtoras do Direito tão ou mais importantes do que o Estado, como o pater familias em Roma, ou as corporações medievais. Se o pai romano tinha o direito até de vender seu filho e de mantê-lo sob seu jugo durante toda a vida, no mundo moderno a emancipação se dá por decurso do prazo, mesmo contra a vontade do pai, a quem tampouco é permitido exagerar nos castigos enquanto titular do pátrio poder. O direito estatal pretende alcançar inclusive relações íntimas, como aquelas de família ou mesmo o chamado 'débito conjugal'.

Por outro lado, a crescente importância das fontes estatais em detrimento das fontes espontâneas e extra-estatais do direito é outra das características da modernidade ${ }^{18}$. Dentre as fontes estatais, temos a lei e a jurisprudência ${ }^{19}$.

das estatísticas do que das monografias e das confissões. De resto, metodologicamente, atribuía às normas do direito um valor instrumental sem par. Por causa de sua generalidade, fixidez e materialidade seriam capazes de revelar os factos sociais mais objectivamente do que o poderiam fazer, por exemplo, os sentimentos e as opiniões, ou seja, as condutas não jurídicas".

${ }^{14}$ Neste sentido, Boaventura de Sousa Santos (In: A crítica da razão indolente - contra o desperdício da experiência, p. 65).

${ }^{15}$ Neste sentido, Boaventura de Sousa Santos (In: A crítica da razão indolente - contra o desperdício da experiência, p. 65).

16 Neste sentido, Boaventura de Sousa Santos (In: A crítica da razão indolente - contra o desperdício da experiência, p. 65).

${ }^{17}$ In: ADEODATO, João Maurício. Revista Ciências Sociais, v. 3, n. 2, p. 264-79.

${ }^{18}$ Segundo Niklas LUHMANN e Raffaele De GEORGI, " la sociedad moderna no está constituida por individuos y que no puede ya ser descrita como si estuviera constituida por indivíduos, sino que debe atribuir a los individuos, en cuanto existencias mentales y corporales, una posición externa. Esta también es una consecuencia necesaria de la diferenciación funcional; $y$, en efecto, esta forma de la difereenciación excluye que los individuos concretos se distribuyan entre los sistemas individuales de funciones, por ejemplo, entre las familias, las casas, los pueblos y las ciudades o los estratos sociales. Ahora cada individuo debe poder participar en todos los sistemas de funciones; como consecuencia, es necesario volver a pensar el nuevo significado que adquire el principio da inclusión social, y 
Também a emancipação da ordem jurídica em relação às outras ordens normativas, a auto-referência do sistema jurídico, existente na modernidade, conduz ao processo de dogmatização do Direito.

A contradição existente entre progresso material e injustiça social - sem que o primeiro elimine ou diminua a segunda -, é explicado por Theodor W. ADORNO ${ }^{20}$, a partir do pressuposto de que a sociedade moderna se rege pelo sistema cuja característica marcante é circunscrever um sistema social fechado sobre si mesmo, o que impede toda e qualquer ação individual ou coletiva para se superar sua lógica perversa e injusta, a lógica do sucesso ou do fracasso, que delega à razão somente a tarefa de adequar tecnicamente os meios a fins que lhe são alheios e impostos ${ }^{21}$.

es necesario además encontrar reglas nuevas para el uso de nuevos conceptos de valor, como liberdad e igualdad. ¿Qué les sucede después a los mismos individuos? Y éste es precisamente el tema sobre el cual sigue siendo necesario llegar a un acuerdo com la ayuda de la nueva distinción entre individuo y sociedad. Esta distinción registra el hecho de que entre el final del siglo XVIII y el inicio del siglo XIX el individuo alcanzó una posición de un nuevo tipo, es decir, la posición de valor supremo ( $y$ cuando se quiere mencionar precisamente este hecho, al individuo se le llama sujeto). A su vez, esta colocación del individuo en una posición que transciende las valoraciones que circulan en la sociedad y que se presenta como su premisa, está condicionada por el hecho de que el cambio radical de las formas de la diferenciación social revoluciona la semántica tradicional de la inclusión y oblica a poner al individuo como elemento externo a la sociedad." (In: LUHMANN, Niklas; GEORGI, Raffaele de. Teoría de la sociedad. 1. ed. em espanhol. Guadalajara (México): 1993, p. 421).

${ }^{19}$ “A jurisprudência e a lei são tão antigas quanto a civilização. Todavia, apenas com o Estado moderno que o processo legislativo - resultando na lei - e o costume jurisprudencial - originando a jurisprudência - passam a preponderar sobre as fontes não estatais do direito, como o contrato, as declarações unilaterais de vontade ou o costume jurídico, que só valem na medida em que constituem fontes complementares, subsidiárias às regras estatais". (In: ADEODATO, João Maurício. Revista Ciências Sociais, p. 264-79).

${ }^{20}$ In: ADORNO, Theodor W. Adorno Vida e Obra - Conceito de lluminismo. São Paulo: Nova Cultural, 1999.

${ }^{21}$ Segundo Jürgen HABERMAS, "Adorno e Horkheimer estão convencidos de que a ciência moderna voltou a si mesma no positivismo lógico e renunciou à pretensão empática de conhecimento teórico em favor da utilidade técnica: "Compreender o dado enquanto tal, descobrir nos dados não apenas suas relações espácio-temporais abstratas, com as quais se possa então agarrá-las, mas, ao contrário, pensá-las como a superfície, como aspectos mediatizados do conceito, que só se realizam no desdobramento do seu sentido social, histórico, humano - toda a pretensão do conhecimento é abandonada'(DE, p. 39; trad., p. 38-9). A crítica exercida antes contra a compreensão positivista da ciência intensifica-se na censura global de que as próprias ciências são absorvidas pela razão instrumental. Tomando como fio condutor a história de Juliette e a Genealogia da moral, Horkheimer e Adorno querem mostrar mais adiante que a razão foi expulsa da moral e do direito, pois com a decomposição das imagens religiosas e metafísicas do mundo, todo critério normativo perdera seu crédito em face da autoridade da ciência, que é a única que restou: 'o fato de ter não encoberto, mas bradado ao mundo inteiro a impossibilidade de apresentar, a partir da razão, um argumento de princípio contra o assassinato ateou o ódio com que os progressistas ainda hoje perseguem Sade e Nietzche'(DE, p. 142; trad., p. 111). A crítica exercida antes contra as reinterpretações meta-éticas da moral torna-se um consentimento sarcástico ao ceticismo ético". (In: HABERMAS, Jürgen. O Discurso Filosófico da Modernidade. O entrelaçamento de mito e esclarecimento: Horkheimer e Adorno. São Paulo: Martins Fontes, 2002, p. 160). 
Entretanto, os avanços tecnológicos e a sociedade globalizada fizeram surgir uma nova era: a da pós-modernidade ${ }^{22}$.

\section{O progresso do mundo contemporâneo e a insuficiência da teoria jurídica originária da modernidade}

No cenário contemporâneo, a sociedade é regida por novos comandos. De um lado, o mundo contemporâneo trouxe um progresso material impressionante, de descobertas e inovações tecnológicas; de outro, grande parte da população mundial permanece no mais completo estado de subdesenvolvimento e abandono.

Ao desenvolvimento e progresso das metrópoles industriais é possível atribuir também o enorme crescimento das classes médias urbanas e, com elas, o destaque da estrela e vilã de nosso século: a cultura de massa, produção cultural destinada aos grandes grupos de consumidores, simples e estereotipada, com objetivos claros e definidos.

A partir do final da primeira metade do século $X X$, com o término da segunda guerra mundial, a sociedade, mobilizada pela propaganda e pelo consumo, pela tecnociência aplicada à informação, passou a assumir novas feições. Abriu-se, então, espaço para a crítica de um ideal de racionalidade institucionalizado.

O desenvolvimento da ciência possibilitou o aumento do saber empírico, colocado a serviço das forças produtivas. A moral, distanciando-se cada vez mais da religião, deu origem a uma ética do trabalho. Posteriormente, com o advento da psicanálise, os mecanismos da repressão foram desvelados, invertendo-se a hierarquia tradicional entre a razão e as paixões com a valorização da espontaneidade e a supremacia do desejo em relação à racionalidade. A

22 Para alguns autores, a modernidade ainda não se esgotou. Ver: Jürgen HABERMAS. (In: Ensayos Políticos.Traducción de Ramón García Cotarelo. 4. ed. Barcelona: Ediciones Península, 2000, p. 265 e ss). No mesmo sentido: Jean CHESNEAUX (In: Modernidade-Mundo. 2. ed. Traduzido por João da Cruz. Petrópolis: Vozes, 1996), afirma que, graças à globalização e à mundialização das mercadorias e da cultura, a modernidade se precipita sobre nosso mundo e é hoje referência tanto para políticos do terceiro mundo como para dirigentes da antiga União Soviética, Chineses ou 'eurocratas'. A ela se reportam também empresários, especialistas da mídia, vendedores, urbanistas e, para além de pequenas especificidades, ela é a mesma em São Paulo, Hong Kong, Milão ou Buenos Aires, metrópoles onde torres verticais se equilibram na perpétua agitação do mundo financeiro, do rush de pedestres, do trânsito congestionado. Neste sentido, o conceito de modernidade tende pois a coincidir com a idéia de 'sociedade complexa', que se refere não só ao Ocidente desenvolvido, mas envolve a humanidade inteira de maneira ambivalente e paradoxal. 
arte, por sua vez, distanciando-se da religião, tornou-se mais autônoma com a produção artística para o mercado.

Segundo Sérgio ROUANET ${ }^{23}$, tais esferas atuando em espaços institucionais próprios como universidades e centros de pesquisa, no caso das ciências, comunidade de fiéis no caso da moral e sistemas de produção, distribuição e consumo no caso das artes - constituem-se elementos funcionais em relação à modernização social, o que não quer dizer que, vez por outra, não exista, entre elas e o próprio sistema social, elementos de contradição.

A pós-modernidade ${ }^{24}$ deslocou - uma da outra - as três grandes áreas da vida histórica: o conhecimento, a política e o desejo. O conhecimento se libertou de suas restrições éticas e amarras e partiu em busca do que antes era considerado "tabu", contando somente com a autoridade de seus poderes críticos e céticos. Com o nome de ciência, desligou-se do ético e do estético, perdendo paulatinamente contato com o valor. A investigação ética, desatrelada do aparelho eclesiástico, viu-se livre para levantar questões da justiça e da dignidade sob perspectivas muito mais abertas.

A arte, deixando de servir o poder político e libertando-se de suas funções no interior da igreja, do tribunal e do Estado, passou a reger-se por suas próprias leis. O seu significado tornou-se, então, meramente suplementar, ligado ao lado afetivo-instintivo não-instrumental da psique, uma espécie de válvula de escape. Sua independência em relação ao ético e ao político, porém, se deu de forma paradoxal na medida em que aconteceu, em função de sua integração ao mercado, sua transformação em mercadoria. A estética, em contraposição, se propôs reverter o processo de divisão das áreas da história, estetizando a verdade e a moral: propondo a arte como uma reconciliação ideal do sujeito com o objeto, do universal e do particular, da liberdade e da necessidade, da teoria e da prática, do indivíduo e da sociedade ${ }^{25}$.

Para Jean François LYOTARD ${ }^{26}$, há em nossos dias rupturas e mudanças que caracterizam e constituem a pós-modernidade. Essas alterações fazem com que ocorra uma crise no conceito de racionalidade inaugurado pelo iluminismo. Para o autor, ciência e sociedade se constituem, em nossa contemporaneidade, numa complexa rede de jogos de

\footnotetext{
${ }^{23}$ ROUANET, Sérgio. As razões do lluminismo, p. 229-31.

${ }^{24}$ Sobre modernidade, escreveu Charles BAUDELAIRE (In: Sobre a modernidade. São Paulo: Paz e Terra, 1996, p. 25), "é o transitório, o efêmero, o contingente; é uma metade da arte, sendo a outra o eterno e o imutável".

${ }^{25}$ In: EAGLETON, Terry. A ideologia da Estética. Traduzido por Mauro Sá Rego da Costa. Rio de Janeiro: Jorge Zahar, 1993, p. 264-6.

${ }^{26}$ In: LYOTARD, Jean François. A condição pós-moderna. Traduzido por José Bragança de Miranda. Lisboa: Gradiva,
} 1998. 
linguagem, com seus próprios conteúdos e regras de legitimação, sem possibilidade de entendimento. A interpretação homogênea dos acontecimentos que, no início da era moderna, se dava através das narrativas científicas ou filosóficas legitimadoras do saber, perdeu sua validade.

A conquista de novos conhecimentos no interior dos 'jogos de linguagem' legitimadores torna-se restrita aos que podem mais, aos que dispõem de melhores condições financeiras, pois o saber está diretamente subordinado ao lucro. O saber, segundo JeanFrançois LYOTARD, está sempre em busca de performance e do aumento de poder de seu usuário, com novas argumentações, novas regras e jogos de linguagem em que o consenso se torna inatingível ${ }^{27}$. Para o autor, o conhecimento, hoje, está sempre se codificando e recodificando das mais diferentes maneiras, em função da transformação das condições técnicas e sociais da comunicação ${ }^{28}$.

Segundo Jean CHESNEAUX ${ }^{29}$, a grande expansão do número de computadores conectados em redes exerce, em nossos dias, a exata função que as estradas de ferro um dia exerceram no sentido de anexar territórios ao mundo capitalista. As pressões financeiras que deslocam o espaço urbano são as mesmas que alteraram, anteriormente, o espaço rural, e os bolsões de modernidade do terceiro mundo são retransmissores do capitalismo mundial, como eram, no passado, as colônias tropicais das potências européias. Mais do que nunca produções e trocas servem para reproduzir o capital. A eficiência das empresas se define pela rentabilidade de seus investimentos e a competitividade de seus produtos. A interpenetração do capital industrial e financeiro é a chave do poderio econômico ${ }^{30}$.

\footnotetext{
${ }^{27}$ In: GOERGEN, P. A crítica da modernidade e a educação. Revista Pro-Posições, v. 7, n. 2, jul. 1996, p. 20

${ }^{28}$ Massimo CANEVACCI (In: Antropologia da Comunicação. São Paulo: Brasiliense, 1988, p. 14-34), confirma o pensamento de Jean-François LYOTARD. Para ele há, realmente, em nossos dias, uma descrença generalizada na inelutabilidade do progresso e um crescente desconforto em relação à fixidez categórica do pensamento de tradição iluminista. Esta crise no conceito de racionalidade, instaurado pela filosofia das luzes, vem, sem dúvida, operando transformações no mundo da representação e do conhecimento. Ainda, segundo ele, as idéias nascem e se reproduzem diretamente das coisas, das mercadorias produzidas pela tecnologia.

${ }^{29}$ CHESNEAUX, Jean. Modernidade-Mundo, p. 35.

30 Sobre o tema ver: Viviane FORRESTER (In: O Horror Econômico. Traduzido por Álvaro Lorencini. São Paulo: UNESP, 1996); Paul VIRILIO (In: A Bomba Informática. Traduzido por Luciano V. Machado. São Paulo: Estação Liberdade, 1999); Pierre LÉVY (In: Cibercultura. Traduzido por Carlos Irineu da Costa. Rio de Janeiro: Editora 34, 1999).
} 
Pelo exposto, observa-se uma profunda modificação no âmbito da sociedade - que possuía características próprias na chamada "modernidade".

A globalização cria relações de interdependência entre as distintas populações do planeta, reorganizando o tempo e a distância na vida social. Ela impõe uma nova estrutura no campo do poder. A forma estatal perde sua primazia ao subordinar-se a um soberano estatal privado 'supra estatal', de caráter difuso.

A fase pós-industrial, por sua vez, coloca no mercado novos materiais químicos e tecnologia informática, permitindo inovações em todos os ramos da produção e novas técnicas de organização produtiva e empresarial.

Através da globalização, deixam de haver fronteiras para os fluxos financeiros de bens e serviços (e esses fluxos são incessantes!). Estabelece-se também a globalização das comunicações. A globalização impõe uma nova estruturação do espaço e das distâncias, por uma parte, e do tempo, por outra. Ela se faz visível na grande superfície comercial. Nos grandes mercados, os produtos agrícolas já não mais estão atrelados às estações do ano nem à localização; oferecem-se roupas, sapatos e produtos da mais variada natureza, produzidos por crianças escravizadas em algum lugar do mundo.

Por outro lado, a fase pós-industrial importa também no surgimento de novas formas de sociedade organizativas. Fala-se, em um primeiro momento, de empresas transnacionais que operam em diversos países. Assim, o capital não conhece pátria. Muitas dessas companhias transnacionais são o que, às vezes, denominam-se de conglomerados, o que significa dizer: ocupam-se da produção de muitos tipos diferentes de bens e serviços.

Assim, pode-se dizer que a força principal da modernidade, força de abertura de um mundo que estava cercado e fragmentado, esgota-se na exata medida em que as mudanças se intensificam e aumenta a densidade em homens, em capitais, em bens de consumo, em instrumentos de controle social e em armas.

Segundo Alain TOURAINE ${ }^{31}$,

(...) este esgotamento da idéia de modernidade é inevitável, já que ela se define não como uma nova ordem, mas como um movimento, uma destruição criadora, para retomar a definição de capitalismo de Schumpeter. 0 movimento atrai aqueles que durante muito tempo se fecharam na imobilidade; ele cansa, torna-se vertigem quando é incessante e não conduz senão à sua própria aceleração. Por ser a modernidade uma noção mais crítica que construtiva, ela requer uma crítica que seja por si mesma hipermoderna, o

\footnotetext{
${ }^{31}$ TOURAINE, Alain. Crítica da modernidade. Traduzido por Elia Ferreira Edel. 3. ed. Rio de Janeiro: Vozes, 1995, p. 100-4. 
que protege contra as nostalgias que, sabemos, tornam facilmente uma aparência perigosa. $O$ esgotamento da modernidade transforma-se com rapidez em sentimento angustiante do sem-sentido de uma ação que não aceita outros critérios que o da racionalidade instrumental. Horkheimer denunciou a degradação da 'razão objetiva' na 'razão subjetiva', isto é, de uma visão racionalista do mundo em uma ação puramente técnica pela qual a racionalidade é colocada ao serviço das necessidades, sejam elas a de um ditador ou as dos consumidores, que não são mais submetidos à razão e a seus princípios de regulamentação da ordem social assim como da ordem natural. Essa angústia leva a uma inversão de perspectiva. Bruscamente a modernidade é denominada 'o eclipse da razão' por Horkheimer e Adorno e todos aqueles por eles influenciados, bem além da escola de Frankfurt.

As condições do crescimento econômico, da liberdade política e da felicidade individual não são mais análogas e interdependentes. A dissociação entre as estratégias econômicas e a construção de um tipo de sociedade, de cultura e de personalidade operou-se muito depressa e é ela que define a idéia de pós-modernidade.

Se a modernidade associou progresso e cultura, opondo culturas ou sociedades tradicionais e culturas e sociedades modernas, explicando todo fato social ou cultural pelo lugar que ocupa sobre o eixo tradição-modernidade, a pós-modernidade dissocia o que havia sido associado.

Gianni VATTIMO ${ }^{32}$ considera duas transformações como fundamentais para definir a pós-modernidade: o fim da dominação européia sobre o conjunto do mundo e o desenvolvimento dos meios de comunicação que deram a palavra às culturas 'locais' ou minoritárias. Desapareceu assim o universalismo que concedia uma importância central aos movimentos sociais que a Europa dos séculos XVIII e XIX supunha que lutavam a favor ou contra a razão e o progresso.

A sociedade industrial ampliou a complexidade sócio-econômica e política, exigindo soluções cada vez mais abstratas e flexíveis, pragmáticas e abertas. Com a transformação dos conflitos individuais em conflitos coletivos entre grupos e classes, a mediação formalizada pela 'práxis social' se torna problemática. Assim, o surgimento desses novos conflitos conduz à necessidade de adequação do Direito. O Direito tende a se "adaptar" e adquire situações próprias à nova situação.

\footnotetext{
${ }^{32}$ VATTIMO, Gianni. En torno a la posmodernidad. Santafé de Bogotá: Anthropos, 1994, p. 12. 
Segundo Juan Ramón CAPELLA ${ }^{33}$, uma nova cultura babélica assiste o confronto de tendências opostas: o impulso à barbarização de todas as relações sociais, que pode acabar em tiranias integrais e catástrofes sociais duradouras, e a enfraquecida tendência a uma posterior radicalização contra as desigualdades estruturais do processo de democratização. Willis Santiago GUERRA FILHO ${ }^{34}$, por sua vez, ao tratar do assunto, refere que

...a pós-modernidade está no sentido de se resgatar uma periodicização, algo que o modernismo, por definição, impede - o atual, o presente, é sempre moderno. Na segunda metade do século em curso, estaríamos vivendo na pósmodernidade, devido ao modo radicalmente diverso como se organiza, econômica e politicamente, a sociedade egressa da modernidade, como uma correlata mudança no conjunto de crenças e pressuposições que formam a mentalidade dos que compõem, bem como pela natureza dos problemas que nela se apresentam. Tem-se a falência da idéia de que o conhecimento científico forneceria ao sujeito a verdade sobre os objetos que se colocavam diante dele. Há uma revalorização de formas pré-modernas, como a retórica, enquanto a doutrina do discurso razoável persuasivo e da hermenêutica, com seu intuito de compreender, mais do que explicar, como também o surgimento de novas formas de pensar, como a interdisciplinaridade, a postura científica crítica e as investigações psicoanalíticas. Pós-modernismo, pós-positivismo e o Direito como Filosofia.

O grande problema jurídico na atualidade é como pensar o Direito, como operar com o Direito neste período de grandes transformações pelo qual se passa, nesta forma de sociedade de que muitos chamam, por uma questão de comodidade, de globalização. Examinar o Direito dentro da globalização implica relacioná-lo com a complexidade, com todos os processos de diferenciação e regulação social que estão surgindo. ${ }^{35}$

Tem-se hoje, em plena forma de sociedade globalizada, ainda uma teoria jurídica originária da modernidade presa à noção de Estado e de norma jurídica ${ }^{36}$. Trata-se de uma teoria que tem como pressuposto teórico e epistemológico o normativismo, que vai difundir-se

\footnotetext{
${ }^{33} J$ Juan Ramon CAPELLA, "una nueva cultura, babélica, presencia el enfrentamiento de tendencias contrarias: el impulso a la barbarización de todas las relaciones sociales, que puede desembocar en tiranías integrales y catástrofes sociales duraderas, y la debilitada tendencia a un ulterior afianzamiento, contra las desigualdades estructurales, del proceso de democratización". In: Fruta prohibida: una aproximación histórico-teorética al estudio del Derecho y del Estado. Madrid: Trotta, 1997, p. 239 e 240.

${ }^{34}$ In: GUERRA FILHO, Willis Santiago. O Poder das Metáforas: homenagem aos 35 anos de docência de Luís Alberto Warat, p. 61 e ss.

${ }^{35}$ Neste sentido: ROCHA, Leonel Severo. Epistemologia Jurídica, p. 185.

${ }^{36}$ Sobre o tema ver: KELSEN Hans. Teoria Pura do Direito. Traduzido por João Baptista Machado. 5. ed. São Paulo: Martins Fontes, 1996.
} 
por todo o Ocidente como matriz teórica que representa o Direito na modernidade ${ }^{37}$. Segundo Leonel Severo ROCHA ${ }^{38}$,

Dessa maneira, quando se ingressa numa nova forma de sociedade globalizada, que também poderia se denominar de transnacionalizada, ou pósmoderna, o problema é o fato de que qualquer perspectiva mais racionalista ligada ao normativismo e ao Estado se torna extremamente limitada. Não se pode, assim, continuar mantendo uma noção de racionalidade no Direito ao se insistir no ideal kelseniano.

Pode-se falar em uma crise do Direito da modernidade. Não se trata apenas de uma deficiência em sua estrutura tradicional, mas uma crise da integração de seus pressupostos dogmáticos para funcionarem dentro da globalização. É preciso relacionar-se o Direito com a política e a sociedade, o que não é fácil. Conforme refere Leonel Severo ROCHA,

Não basta apenas dizer-se que é preciso pensar-se o Direito juntamente com a política e a sociedade; quanto a isso, há um consenso. O problema está em atribuir um sentido pragmático a essa assertiva.

É preciso romper limites. As velhas seguranças e as evidências estabelecidas por uma forma de pensamento começam a produzir perplexidades e angústias para articular um programa de transformação da sociedade. Este desejo de inovação é o que caracteriza a democracia. ${ }^{39}$

\section{O paradigma cientificista e o direito processual civil moderno: a necessidade de superação}

O paradigma para o processualista moderno é de que o sentido da lei é unívoco. A verdade está sempre presente e deve apenas ser desvelada, como se fosse um filme fotográfico a ser revelado. Ao juiz cabe descobrir esta verdade única e proclamá-la na sentença. Na verdade, a tarefa é um tanto simples, pois o juiz conta com uma lei clara e precisa e com uma situação concreta, bastando um exercício de silogismo para chegar à decisão, que será sempre a correta, pois se a lei é precisa, não há espaço para questioná-la.

\footnotetext{
${ }^{37}$ Neste sentido: ROCHA, Leonel Severo. Epistemologia Jurídica, p. 185.

${ }^{38}$ Neste sentido: ROCHA, Leonel Severo. Epistemologia Jurídica, p. 186.

39 Leonel Severo ROCHA (In: Epistemologia Jurídica, p. 87) entende que a hermenêutica jurídica apresenta lacunas teóricas. Segundo ele, ela não explica suficientemente o que é sociedade.
} 
O abandono da vertente aristotélica e o desprezo pela dialética, privilegiando os juízos

lógicos e as verdades absolutas, formam as bases do processo de conhecimento, consagrado pelo sistema racionalista, que afasta os juízos de verossimilhança.

Ainda sobre a possibilidade de transformar o direito em uma ciência tão precisa quanto as ciências exatas, Gottfried Wilhelm LEIBNIZ $^{40}$ sustenta, de fato, a possibilidade de que a ciência do direito contenha uma exatidão e demonstrabilidade tanto quanto um teorema matemático. Para este autor, a moral e a ciência natural do direito podem ter a mesma clareza e, com isso, podem ser objeto de demonstração, observado o mesmo rigor com que demonstra um postulado matemático.

Enrico Tullio LIEBMAN $^{41}$, doutrinador que exerceu forte influência no processo civil brasileiro, ao tratar da função jurisdicional, conserva traços do pensamento racionalista:

A função jurisdicional consta fundamentalmente de duas espécies de atividade, muito diferentes entre si: de um lado, o exame da lide posta em juízo, para o fim de descobrir e formular a regra jurídica concreta que deve regular o caso; de outro, as operações práticas necessárias para efetivar o conteúdo daquela regra, para modificar os fatos da realidade de modo a que se realize a coincidência entre a regra e os fatos. Por conseguinte, a natureza e os efeitos dos atos relativos diferem profundamente; na cognição a atividade do juiz é prevalentemente de caráter lógico: ele deve estudar o caso, investigar os fatos, escolher, interpretar e aplicar as normas legais adequadas, fazendo um trabalho intelectual que se assemelha, sob certo ponto de vista, ao de um historiador, quando reconstrói e avalia os fatos do passado. $O$ resultado de todas estas atividades é de caráter ideal, porque consiste na enunciação de uma regra jurídica que, reunindo certas condições, se torna imutável (coisa julgada). Na execução, ao contrário, a atividade do órgão é prevalentemente prática e material, visando produzir na situação de fato as modificações acima aludidas.

Observa-se que o autor chega a tratar com menos ênfase o processo de execução, que é aquele em que o direito realmente será satisfeito, já que o processo de cognição, por mais

\footnotetext{
40 In: "La doctrina del derecho es de la índole de aquellas ciencias que no dependen de experimentos, sino de definiciones, no de las demostraciones de los sentidos, sino de las de la razón; y son, por así decirlo, propias del derecho y no el hecho. Así, pues, como la justicia consiste en un cierto acuerdo y proporción, puede entenderse que algo es justo, aunque no haya quién ejerza da justicia, ni sobre quién recaiga, de manera semejante a como los cálculos numéricos son verdaderos, aunque no aya quién numera ni qué numerar. A la manera como se puede predecir de una cosa, de un máquina o de un Estado que, si han de existir, ha de ser hermosa eficaz y feliz, aunque nunca hayan de existir. Por tanto, no es sorprendente que los principios de estas ciencias sean verdades eternas". (In: LEIBNIZ, Gottfried Wilhelm. Los Elementos del Derecho Natural. Traduzido por Tomás Guillén Vera. Madrid: Tecnos, 1991, p. 70.)

${ }^{41}$ In: LIEBMAN, Enrico Tullio. Processo de Execução. São Paulo: Saraiva, 1968, p. 37.
} 
que declare o direito e condene o réu, serve apenas como documento para aparelhar outro processo, o de execução, no qual concretamente haverá satisfação.

Em grande número de situações, os pressupostos do mundo jurídico não possuem qualquer vinculação do direito com os fatos ${ }^{42}$. 0 direito se refugia no normativismo puro, do qual acabam resultando conceitos anacrônicos. Na aplicação da teoria dualista do ordenamento jurídico, Giuseppe CHIOVENDA ${ }^{43}$ sustenta que o ordenamento jurídico se divide em direito material e direito processual, sendo que o primeiro estabelece as regras abstratas, que se tornam concretas no momento em que ocorre o fato enquadrado nas suas previsões, ocorrendo tudo isto de forma totalmente desvinculada do juiz.

O processo, então, tem por finalidade única a atuação da vontade do direito, não contribuindo em nada para a realização do mundo da vida ${ }^{44}$. A influência das idéias jurídicofilosóficas predominantes no século XIX se mostram presentes na doutrina CHIOVENDIANA sobre a jurisdição, pois o autor consegue vislumbrar as funções de legislar e de aplicar a lei como praticamente antagônicas.

Segundo Ovídio Araújo BAPTISTA DA SILVA ${ }^{45}$, com a aplicação da lógica às ciências explicativas, ocorre uma verdadeira supressão da possibilidade de o julgador descobrir a verdade. O julgador fica tolhido de toda e qualquer autonomia crítica que possa ter como conseqüência a construção de mais do que uma solução para o caso prático, todas elas com validade e tomando por base critérios valorativos distintos. Tal procedimento, aliás, não teria razão de ser, pois a justiça está representada no texto de lei e, por isso, lei injusta não existiria.

Para o mundo racionalista ${ }^{46}$, é imprescindível à formação de uma ciência processual o abandono dos juízos de probabilidade, devendo prevalecer apenas as verdades claras e

\footnotetext{
${ }^{42}$ Sobre o tema vide: SILVA, Ovídio Araújo Baptista da. Jurisdição e Execução na Tradição Romano-Canônica)

${ }^{43}$ In: CHIOVENDA, Giuseppe. Instituições de direito processual civil. Traduzido por J. Guimarães Menegale. 3. ed. São Paulo: Saraiva, 1969. v. I, II e III.

44 “Toda norma encerrada na lei representa uma vontade geral, abstrata, hipotética, condicionada à verificação de determinados fatos, que, em regra, podem multiplicar-se indefinidamente. Cada vez que se verifica o fato ou grupo de fatos previstos pela norma, forma-se uma vontade concreta de lei, ao tempo em que da vontade geral e abstrata nasce uma vontade particular que tende a atuar no caso determinado." (CHIOVENDA, Giuseppe. Instituições de direito processual civil, p. 18)

45 “Assim como o juiz servirá de oráculo para o soberano que, através dele, profere o julgamento, igualmente estabelece Hobbes a inevitável premissa de que a lei, sendo a expressão da justiça, haverá de conter uma única solução correta, cabendo ao julgador apenas proclamá-la na sentença." (In: SILVA, Ovídio Araújo Baptista da. Jurisdição e Execução na Tradição Romano-Canônica, p. 119)

${ }^{46}$ Trata-se da racionalidade instrumental.
} 
evidentes. Como fator determinante para o sucesso do normativismo, imperioso foi o abando do estudo de caso e a tradição ${ }^{47,48}$.

Por outro lado, no mundo "racionalista", a busca pela realização do direito é inviável, na medida em que o critério de determinação do justo e do injusto são tarefas delegadas ao legislador e não ao juiz.Uma vez considerado o direito uma ciência racional que prescinde da experiência, tão exata quanto um teorema matemático, é preciso eliminar todo e qualquer probalismo inerente às concepções clássicas, à filosofia aristotélica e aos juízos retóricos. Ainda hoje o Direito Processual Civil possui fortes traços do pensamento racionalista.

O positivismo jurídico caracteriza-se por sua posição contrária a todas as formas de metafísica jurídica; portanto, afastando completamente as teorias do Direito Natural. Fora da experiência, da realidade ou do direito positivo, não existe direito. Reforça esta doutrina, também, a supremacia da legislação como fonte superior às demais fontes de direito. $\mathrm{O}$ positivismo jurídico seguiu várias formas distintas, sendo possível falar-se em positivismo jurídico inglês, positivismo jurídico alemão, positivismo jurídico francês, neopositivismo ou positivismo lógico (também conhecido como doutrina do Círculo de Viena). Entretanto, em linhas gerais, caracteriza-se este pensamento por ser antimetafísico e antijusnaturalista.

\section{Segundo Jürgen HABERMAS ${ }^{49}$,}

- positivismo jurídico pretende, ao contrário, fazer jus à função da estabilização de expectativas, sem ser obrigado a apoiar a legitimidade da decisão na autoridade impugnável de tradições éticas. Ao contrário das escolas realistas, os teóricos Hans Kelsen e H. L. A. Hart elaboram o sentido normativo próprio das proposições jurídicas e a construção sistemática de um sistema de regras destinado a garantir a consistência de decisões ligadas a regras e tornar o direito independente da política. Ao contrário dos hermeneutas, eles

\footnotetext{
47 Segundo Alasdair MACINTYRE (In: Justiça de quem? Qual Racionalidade?, p. 399), "toda tradição se expressa num grupo particular de asserções e ações e, através delas, em todas as particularidades de uma língua e de uma cultura específicas. A invenção, a elaboração e a modificação dos conceitos, através dos quais os que fundam e os que herdam uma tradição a compreendem, estruturam-se numa língua e não em outra, inevitavelmente. Quando os adeptos dessa tradição, pela primeira vez, planejam estendê-la a uma outra comunidade lingüística, eles devem, em primeiro lugar, identificar, na nova língua, não apenas os tipos de asserção a serem reconhecidos como instâncias que dizem o mesmo que certas sentenças na língua, ou línguas, através da qual a tradição se expressou até agora, mas também o que é que não pode ser dito na nova língua, o que é, até então intraduzível".

${ }^{48}$ Neste sentido, a lição de Giuseppe CHIOVENDA (In: Instituições de direito processual civil, p. 63): “Uma coisa é dizer-se que renovadas condições econômicas, sociais, políticas, culturais determinam correntes e tendências novas que lentamente dispõem a doutrina a novas interpretações da lei velha, e que o juiz, como jurisperito, participa incidentemente dessa renovação. Outra coisa é considerar isso como mister do juiz, perigosa máxima que pode encorajar as interpretações individuais e cerebrinas. Com dobrada razão, podemos dizê-lo das doutrinas inspiradas na maior liberdade do julgador (a chamada escola do direito livre) e que a exageraram ao ponto de admitir um poder de correção da lei. Os juízes rigorosamente fiéis à lei conferem aos cidadãos maior garantia e confiança do que os farejadores de novidades em geral subjetivas e arbitrárias."

${ }^{49}$ In: HABERMAS, Jürgen. Direito e Democracia - entre facticidade e validade, v. I, p. 250.
} 
sublinham o fechamento e a autonomia de um sistema de direitos, opaco em relação a princípios não jurídicos. Com isso, o problema da racionalidade é decidido a favor da primazia de uma história institucional reduzida, purificada de todos os fundamentos de validade suprapositivos. A legitimação da ordem jurídica em sua totalidade é transportada para o início, isto é, para uma regra fundamental ou regra de conhecimento, a qual legitima tudo, sem ser, porém, passível de uma justificação racional; ela tem que ser assimilada faticamente como parte de uma forma de vida histórica, portanto, conforme o costume.

A conseqüência do comprometimento da ciência processual com o racionalismo é a transformação do processo em uma ciência em busca da verdade, sem que exista qualquer compromisso com a justiça concreta. Por esta razão, obviamente os juízos de cognição sumária passam a ser totalmente rechaçados, e a cognição plenária, exaustiva e infinita, a mais adequada para a busca da verdade. Tal pensamento busca privilegiar, a todo custo, a segurança jurídica.

$$
\text { Neste sentido leciona Francesco CARNELUTTI }{ }^{50} \text { que }
$$

... a semente da verdade necessita, às vezes, de anos, ou mesmo de séculos, para tornar-se espiga (veritas filia temporis) (...) O processo dura; não se pode fazer tudo de uma única vez. É imprescindível ter-se paciência. Semeia-se, como faz o camponês; e é preciso esperar para colher-se. Ao lado da exigência de atenção, coloca-se a paciência entre as virtudes inafastáveis do juiz e das partes. Infelizmente estas são impacientes por definição; impacientes como os doentes, visto que também sofrem. Uma das tarefas dos defensores é aquela de inspirar-lhes a paciência. O slogan da justiça rápida e segura, que anda na boca de políticos inexperientes, contém, lamentavelmente, uma contradição in adiecto: se a justiça é segura não é rápida, se é rápida, não é segura.

Em seus ensinamentos, o doutrinador italiano retrata o pensamento racionalista, que privilegia a máxima duração do processo como medida capaz de assegurar a segurança jurídica tão proclamada.

Como já restou evidenciado, a idéia de que as instituições processuais possam ser neutras e livres de compromisso com a história e com o contexto cultural e social é falsa. 0 direito tem que existir a partir de um contexto cultural, como um elemento de movimento social e cultural cada vez mais amplo e ultrapassando as fronteiras físicas dos territórios. Nicolai HARTMANN $^{51}$, ao tratar do tema, refere que

Nenhuma época pode ter por base pontos de vista que não sejam os seus. Naturalmente, estes não são absolutos, mas, sim, historicamente condicionados, e outras épocas terão razão se os abandonarem e substituírem pelos seus. Mas também eles estarão, por sua vez, condicionados.

\footnotetext{
${ }^{50}$ In: CARNELUTTI, Francesco. Diritto e processo. Napoli: Morano, 1958, p. 154.

${ }^{51}$ In: HARTMANN, Nicolai. A filosofia do idealismo alemão. Lisboa, 1960, p. 303. 
Na doutrina pátria, é incontestável a adesão dos autores brasileiros ao pensamento racionalista $^{52}$ de ordinarização do processo. A maioria ${ }^{53}$ se convenceu de que a longa duração do processo é capaz de garantir uma decisão melhor e uma "ampla" defesa. Tais idéias têm uma explicação se pensarmos na possibilidade de alguém intencionalmente ingressar em juízo e mover máquina judiciária por pura e simples aventura. Contudo, esta não é a regra geral.

Ainda no tocante ao aspecto de desvalorização do processo civil, Francisco Cavalcanti PONTES DE MIRANDA ${ }^{54}$ também não aceita a função do processo civil ${ }^{55}$ meramente instrumental ${ }^{56}$, ou de outros, que consideravam as regras jurídicas como secundárias, ao passo que as normas de direito material seriam as primárias:

Legislação e Justiça seriam funções sucessivas, em ordem decrescente. Não é aqui o lugar para se criticar tão defeituosa compreensão da atividade jurisdicional, nem para chamar a atenção, o que seria fácil, para a arbitrariedade separativa que faz o legislador o único foco da elaboração jurídica, e da justiça atividade de segunda plana, mecânica e incapaz de criação. À base de tudo isso está a inadmissível identificação de direito e lei. 0 legislador faz a lei. O direito é feito pelo legislador e por outros aparelhos jurisferantes, dentre os quais está o juiz, desde que não se apague a origem democrática da lei, principio básico nos países civilizados.

\footnotetext{
52 Dentre estes autores, destacam-se: Vicente GRECCO FILHO (In: Direito Processual Civil Brasileiro. São Paulo: Saraiva, 2003); Humberto THEODORO JÚNIOR (In: Curso de Direito Processual Civil. Rio de Janeiro: Forense, 1990); SANTOS, Moacyr Amaral (In: Primeiras Linhas de Direito Processual Civil. São Paulo: Saraiva, 2000); Arruda ALVIM (In: Manual de Direito Processual Civil. São Paulo: Revista dos Tribunais, 1997); Cândido Rangel DINAMARCO (In: Instituições de Direito Processual Civil. São Paulo: Malheiros, 2003).

53 “... mas sempre cuidando que não se mutilem as garantias, quer de observância do Direito objetivo, quer de respeito aos direitos subjetivos das partes ou de terceiros. O acerto da decisão prima por sua presteza. É preciso que a ligeireza não se converta em leviandade, que a pressa não acarrete a irreflexão. $O$ juiz deve buscar a rápida solução do litígio, mas tem de evitar o açodamento, o afogadilho, a sofreguidão. Deve ser destro, sem ser precipitado; pontual, sem imprudência. O juiz inconsiderado é ainda pior do que o vagaroso. A observância rigorosa das formas e prazos legais é a melhor receita para conciliar a rapidez e a segurança." (In: TORNAGHI, Hélio. Comentários ao Código de Processo Civil. São Paulo: Revista dos Tribunais, 1975, v. I, p. 382)

${ }^{54}$ In: PONTES DE MIRANDA, Francisco Cavalcante. Tratado das Ações - Ações Mandamentais. São Paulo: Revista dos Tribunais, 1976. v. VI. t. I, p. 256.

${ }^{55}$ A respeito do tema, vide: PONTES DE MIRANDA, Francisco Cavalcante. Sistema de ciência positiva do direito. 2. ed. Rio de Janeiro: Borsoi, 1972.

${ }^{56}$ Segundo Antônio Maria de Freitas Iserhardt (In: "Sistemas jurídicos, ciência do direito e direito: sociologismo jurídico pontensiano versus normativismo jurídico kelseniano". In: Anuário do Programa de Pós-Graduação em Direito. Mestrado e Doutorado. São Leopoldo: Ed. Unisinos, 2003, p. 27-40), "em Pontes, o direito é produto dos círculos sociais, das coletividades, pré-existindo à sociedade e sendo mesmo anterior ao Estado, o que contraria o aforismo que diz onde há sociedade aí existe o direito, legado romano incompadecente com a postura que defende o surgimento do direito onde houve para andrógino, estendendo-se ao clã, fratria, tribo, sociedade em permanente adaptação crescente, experimentando alargamento cada vez maior até atingir a integração do círculo mais amplo, que é a humanidade, fatalidade sociológica. O conceito de direito no autor apresenta nítido substrato sociológico, na medida em que não concebe a existência de regra jurídica fora dos muros do social, lugar de onde a mesma é extraída para ser imediatamente devolvida, pois visa a regras fatos".
} 
A oposição tem por fim criticar a própria divisão entre legislação e justiça e a negação de atividade criadora dos juízes.

O pensamento do século XX se volta para a exaltação da estética da ação, do movimento como valor em si mesmo, o que, nas palavras de Gregorio ROBLES, transformou-o em um século fundamentalmente destrutivo ${ }^{57}$. O autor critica a adoção do formalismo e do instrumentalismo como ideais.

Ao mencionar a crise do modelo processual que vê o processo mero instrumento, J. J. CALMON DE PASSOS ${ }^{58}$ refere que, por conseqüência do movimento de racionalização do direito e, também, do processo, doutrinadores como CHIOVENDA, ZANZUCCHI e CALAMANDREI sequer mencionavam a instrumentalidade como um dos princípios fundamentais do processo. O uso de termos como reintegração do direito objetivo revelam que o processo servia como que para completar alguma outra coisa, a lei. O Estado, ao formalizar a lei, não faz tudo o que é necessário para que aquela seja cumprida e observada, sendo imprescindível o processo para tanto. O processo, então, passa a ser uma peça importante, já que de nada adianta existir um

\footnotetext{
57 "La estética de la acción conduce a la exaltación del poder como instancia indestructible y antropológicamente extensible a todos los ámbitos de la vida, de poder desligado de su fundamento, esto es, de su razón moral, del poder elevado a razón sí mismo, del poder autocomplaciente. La última versión de esta destructiva - también autodestructiva - mentalidad, es la concepción formal o procedimentalista de la democracia. Si la democracia es tan sólo un procedimiento entonces lo importante es el número de votos, el poder cuantitativamente considerado, no el peso de las razones imposibles de medir. Y quizá gana quien mejor miente. En este contexto las sagradas palabras (democracia, derechos humanos, justicia) pueden convertirse en instrumentos de poder cínicamente instrumentalizados, de hecho así sucede en ocasiones y, en ello, si algún día hemos de salir de esta situación para conquistar una concepción moral de la democracia, habremos de abandonar la estética de la acción y sustituirla por la estética de las concepciones morales." (ROBLES, Gregorio. Los derechos fundamentales y la ética en la sociedad actual. Madrid: Editorial Civitas, S.A., 1995, p. 15 e ss)

58 "O velho processo do praxismo, desqualificado e menor (este, sim, meramente instrumental) revestiu-se, a partir do século XIX, do caráter de ciência jurídica, mediante o trabalho dos que lhe teorizaram a dogmática conceitual, avançando, no século XX, até ser vista como integrado à substância mesmo do jurídico, falando-se hoje, inclusive, em um status civillisprocessualis, dimensão nova acrescida à cidadania em sua compreensão anterior. Se na concepção pré-moderna foi admissível atribuir-se-lhe o caráter de mero instrumento, porquanto se afirmava preexistente e predominante o direito material identificado como direito natural divino, a crise experimentada por essa compreensão, na modernidade, determinaria, necessariamente um novo modelo de pensar o processo. Com a transição para o direito natural racional, produzido pelos homens, mas sob o império das leis da razão (o conteúdo normativo da razão prática kantiana) se foi descartando o direito natural divino, substitui a conviç̧ão antiga, representada pela crença num direito prévio a ser apenas explicitado pelos homens em termos de racionalidade. Deixou de ser visto o processo como mero instrumento, impotente para interferir na substância mesma do direito, isto porque ele próprio, processo, enquanto direito, devia submeter-se, tanto quanto o direito material, às leis da razão (o direito natural racional). Daí haver a doutrina acentuado sua interconexão substancial com o direito material, de que passou a ser uma extensão, vale dizer, tão submetido, quanto ele, às leis da razão, sem o que se desqualificaria enquanto direito, interferindo, ainda, e negativamente, na racionalidade inerente àquele. Esse entendimento foi que levou os construtores das bases da dogmática do direito processual, que lhe asseguraram, inclusive, autonomia teórica, a jamais mencionarem a instrumentalidade como um de seus princípios fundamentais." (In: CALMON DE PASSOS, J. J. Instrumentalidade do processo e devido processo legal. Revista de Processo, São Paulo, v. 102, 2001, p. 60)
} 
rol de direitos materialmente codificados e reconhecidos se não houver um meio, um instrumento de realização desses direitos, mormente em uma sociedade onde a autodefesa não é mais permitida. Segundo Joan Picó JUNOY ${ }^{59}$,

A ideologia social, emergente neste século na Europa, leva junto o fenômeno da 'socialização' do processo civil que, com o objetivo de incorporar aos clássicos princípios do liberalismo determinadas exigências do Estado Social de Direito, evidencia a distinção entre objeto do processo e processo como instrumento idôneo para atingir a efetiva e real tutela, pelo Estado, dos interesses litigiosos.

Mesmo quando o processo civil é tomado em seu instrumental, ele acaba por refletir os valores priorizados pela sociedade no momento de sua vigência. Por esta razão, é imperioso o reconhecimento, de forma unânime, de que a função de julgar é muito mais do que aplicar a letra fria da lei, é preciso superar a idéia do juiz boca da lei, decidindo-se diferente, com os olhos para o futuro ${ }^{60}$. Mais do que isso, é preciso que o direito seja considerado em conjunto com todas as outras ciências que o permeiam. Ao contrário do isolamento pregado pelos juristas da Idade Moderna, é mais do que hora de se deixar o direito impregnar pelas questões que the são as verdadeiras formadoras. Os anseios da sociedade, a influência da economia, as repercussões da globalização, tudo isso está no direito e não é possível se fechar os olhos para esta realidade.

Neste sentido, a crise do processo pode ser identificada a partir do momento em que o valor segurança deixa de ter o maior peso na balança dos valores e cede lugar a outros, tão importantes quanto ele ${ }^{61}$. Neste aspecto, os direitos fundamentais assumem grande relevo.

\footnotetext{
59 “La ideologia social, emergente en el presente siglo, lleva consigo en Europa el fenómeno de la 'socialización' del proceso civil, que con el objetivo de incorporar a los clásicos principios del liberalismo determinadas exigencias del Estado Social de Derecho, pone de manifesto la distinción entre objeto del proceso y proceso como instrumento idóneo para alcanzar la efectiva y real tutela, por parte del Estado, de los intereses litigiosos." (PICÓ JUNOY,Joan. "Los Principios del nuevo proceso civil español". Revista de Processo, São Paulo, v. 103, 2001, p. 64)

${ }^{60}$ Esta afirmação não significa dizer que se deva eliminar a legislação de nosso sistema; muito pelo contrário. A atividade jurisdicional complementa a atividade legislativa, não simplesmente repetindo-a mas também criando-a.

${ }^{61}$ Sergio CHIARLONI (In: "Ruolodellagiurisprudenza e attivitàcreative di nuovodiritto". RivistaTrimestrale di Diritto e ProceduraCivile, v. 56, n. 1, p. 1-16, marzo. 2002), refere que "oggi à universalmente diffusalacansapevolezzachel'attività di creazionedeldiritto. Il giudice non è piùvissuto come lamiticabouche de laloi, formula storicamentecondizionata nata Oltrape in unperiodo in cuiladottrinadelladivisione dei potericostituivailsegnocheilpotere era concretamente diviso tralaborghesiarivoluzionariacheavevaconquistatoil legislativo e i resiuifeudalidellostatoassoluto ancora incombenti sul giudiziario. La espressioni 'diritto vivente' e 'dirittogiurisprudenziale', monetaspiccioladeldiscorsogiuridico, ci rammentano ad ogni passo questasemplice e ormaibanaleverità: ilgiudice non solo creaildirittodel caso conceetoattraversol'attività di sussunzione dei fattiaccertatinellesingolefattispecielegali (creandoinsiemecosinel tempo undiritto dei casiidentici o analoghiche non potrebbeessereappannaggiodellegislatore, a meno di immaginarlocapace di abbandonarsi as unimpossibilefuroreanalitico); ilgiudicecreaanche regole nuovederivandole dai principi, oppure aumentando l'estensione di clausolegenerali, e ancora dando rilievoall'equità, o infinelegittimando regole emergentidallaprassi,
} 
Ocorre que, neste sensível processo de alteração nos pesos desses valores, que muitas vezes não é percebida por determinados operadores do direito, a resposta que o judiciário dá à sociedade nem sempre é a esperada, causando, em alguns casos, a frustração. Segundo Augusto M. MORELLO ${ }^{62}$,

Onde quer que seja, multiplicam-se as denúncias de insatisfação pelo serviço da justiça. A importância do problema e a necessidade de atingir conquistas cumulativas indicam a conveniência de focar com a maior claridade possível um fenômeno que, claro está, não é simples, tem muitos rostos, complicações internas e fatores de pressão externa aos do serviço em si... Anunciam-se mudanças, inovações, uma modernização que vá de encontro a uma crise manifesta, palpável, que hoje domina a cena dessa 'administração' (Poder) fundamental para a paz social e a consolidação do Estado de Direito, com tudo o que traz para que não fique apenas na superfície, no formal, ao invés de estampar-se num Estado de Justiça.

Pensadores mais atuais, como Ronald DWORKIN, ao formularem suas teorias para o direito, tentaram evitar as falhas do positivismo, mostrando que a adoção de direitos concebidos deontologicamente podem satisfazer simultaneamente as exigências da segurança jurídica e da aceitabilidade racional. Contra o positivismo, Ronald DWORKIN afirma a possibilidade e a necessidade de decisões corretas, cujo conteúdo seja legitimado por princípios. A razão prática emerge no ponto de vista moral e se articula numa norma fundamental. Em Ronald DWORKIN, a norma fundamental goza do status de um direito natural. Nem todos os direitos subjetivos valem de forma absoluta, porém cada direito coloca barreiras ao cálculo do proveito e dos custos na realização de fins coletivos, os quais se justificam a partir do princípio do igual respeito por cada um.

secondo una tassonomia recentemente formulata". Veja-se, por outro lado, os comentários de Carlos Alberto Álvaro de OLIVEIRA (In: Efetividade e Processo de Conhecimento. Revista de Processo, São Paulo: Revista dos Tribunais, v. 96, p. 65), acerca da renovação trazida pelos estudiosos a partir dos anos cinqüenta do século $X X:$ " $A$ partir dos anos cinqüenta do século $\mathrm{XX}$, com a renovação dos estudos de lógica jurídica e a ênfase emprestada ao sentido problemático do direito, resgata-se em certa medida a dimensão retórica e dialética do processo. Tal fenômeno ocorreu exatamente quando - já prenunciando o pós-modernismo - mais agudos e prementes se tornavam os conflitos de valores e mais imprecisos e elásticos os conceitos."

62 "Por doquier se multiplican las denuncias de insatisfación por el servicio de la justicia. La importancia del problema y la necesidad de alcanzar logros acumulativos, señalan la conveniencia de centrar con la mayor claridad posible un fenómeno que, desde luego, no es simple, tiene muchos rostros, complicaciones internas y factores presionantes externos al del servicio en sí (...) Se anuncian cambios, innovaciones, una modernización que embista a una crisis manifiesta, palpable, que domina hoy la escena de esa 'administración' (Poder) fundamental para la paz social y la consolidación del Estado de Derecho, com todo lo que ello porta para que no se queden sólo en la superficie, lo formal, en lugar de plasmarse en un Estado de Justicia." (MORELLO, Augusto M. Estudios de Derecho Procesal I. Buenos Aires: Abeledo-Perrot S.A., p. 588) 


\section{REFERÊNCIAS BIBLIOGRÁFICAS}

ADEODATO, João Maurício. Revista Ciências Sociais, v. 3, n. 2, p. 264-79.

ADORNO, Theodor W.Adorno Vida e Obra - Conceito de lluminismo. São Paulo: Nova Cultural, 1999.

ALVIM, Arruda. Manual de Direito Processual Civil. São Paulo: Revista dos Tribunais, 1997.

BAUDELAIRE, Charles. Sobre a modernidade. São Paulo: Paz e Terra, 1996.

CALMON DE PASSOS, J. J. Instrumentalidade do processo e devido processo legal. Revista de Processo, São Paulo, v. 102, 2001.

CANEVACCI, Massimo. Antropologia da Comunicação. São Paulo: Brasiliense, 1988.

CAPELLA, Juan Ramon. Fruta prohibida: una aproximación histórico-teorética al estudio del Derecho y del Estado. Madrid: Trotta, 1997.

CARBONNIER, Jean. Sociologia Jurídica. Coimbra: Almedina, 1979.

CARNELUTTI, Francesco. Diritto e processo. Napoli: Morano, 1958.

CHESNEAUX, Jean. Modernidade-Mundo. Petrópolis: Vozes, 1996.

CHIARLONI, Sergio. Ruolodellagiurisprudenza e attivitàcreative di nuovodiritto.

RivistaTrimestrale di Diritto e Procedura Civile, v. 56, n. 1, p. 1-16, marzo. 2002

CHIOVENDA, Giuseppe. Instituições de direito processual civil. Traduzido por J. Guimarães Menegale. 3. ed. São Paulo: Saraiva, 1969. v. I, II e III.

DESCARTES, René. Discurso do Método e as Paixões da Alma. Lisboa: Sá Costa, 1984.

HARVEY, David. Condição pós-moderna. 6. ed. São Paulo: Loyola, 1996.

DINAMARCO, Cândido Rangel. Instituições de Direito Processual Civil. São Paulo: Malheiros, 2003.

EAGLETON, Terry. A ideologia da Estética. Traduzido por Mauro Sá Rego da Costa. Rio de Janeiro: Jorge Zahar, 1993.

FORRESTER, Viviane. O Horror Econômico. Traduzido por Álvaro Lorencini. São Paulo: UNESP, 1996.

GOERGEN, P. A crítica da modernidade e a educação. Revista Pro-Posições, v. 7, n. 2, jul. 1996. 
GRECCO FILHO, Vicente. Direito Processual Civil Brasileiro. São Paulo: Saraiva, 2003.

GUERRA FILHO, Willis Santiago. O Poder das Metáforas: homenagem aos 35 anos de docência de Luís Alberto Warat. Porto Alegre: Livraria do Advogado, 1998.

HABERMAS, Jürgen. Ensayos Políticos.Traducción de Ramón García Cotarelo. 4. ed. Barcelona: Ediciones Península, 2000.

HABERMAS, Jürgen. Direito e Democracia - entre facticidade e validade, v. I. Tradução de Flávio BenoSiebeneichler. Rio de Janeiro: Tempo Brasileiro, 2003.

HABERMAS, Jürgen. O Discurso Filosófico da Modernidade. O entrelaçamento de mito e esclarecimento: Horkheimer e Adorno. São Paulo: Martins Fontes, 2002.

HARTMANN, Nicolai. A filosofia do idealismo alemão. Lisboa, 1960.

ISERHARDT, Antônio Maria de Freitas. Anuário do Programa de Pós-Graduação em Direito. Mestrado e Doutorado. São Leopoldo: Ed. Unisinos, 2003, p. 27-40.

KELSEN Hans. Teoria Pura do Direito. Traduzido por João Baptista Machado. 5. ed. São Paulo: Martins Fontes, 1996.

LEIBNIZ, Gottfried Wilhelm. Los Elementos del Derecho Natural. Traduzido por Tomás Guillén Vera. Madrid: Tecnos, 1991.

LÉVY, Pierre. Cibercultura. Traduzido por Carlos Irineu da Costa. Rio de Janeiro: Editora 34, 1999.

LIEBMAN, Enrico Tullio. Processo de Execução. São Paulo: Saraiva, 1968.

LUHMANN, Niklas; GEORGI, Raffaele de. Teoría de la sociedad. 1. ed. em espanhol. Guadalajara (México): 1993.

LYOTARD, Jean François. A condição pós-moderna. Traduzido por José Bragança de Miranda. Lisboa: Gradiva, 1998.

MACINTYRE, Alasdair. Justiça de quem? Qual Racionalidade? [1988] Tradução Marcelo Pimenta. São Paulo: Loyola, 1991.

MORELLO, Augusto M. Estudios de DerechoProcesal: nuevas demandas, nuevasrespuestas II. Buenos Aires: Abeledo-Perrot, 1998, p. 668-1372.

OLIVEIRA, Carlos Alberto Álvaro de. Efetividade e Processo de Conhecimento. Revista de Processo, São Paulo: Revista dos Tribunais, v. 96.

PATTERSON, Dennis. Law \& Truth. New York: Oxford University Press, 1996. 
PICÓ JUNOY,Joan. "Los Principios del nuevo proceso civil español". Revista de Processo, São Paulo, v. 103, 2001.

PONTES DE MIRANDA, Francisco Cavalcante. Sistema de ciência positiva do direito. 2. ed. Rio de Janeiro: Borsoi, 1972.

PONTES DE MIRANDA, Francisco Cavalcante. Tratado das Ações - Ações Mandamentais. São Paulo: Revista dos Tribunais, 1976. v. VI. t. I.

ROBLES, Gregorio. Los derechos fundamentales y la ética en la sociedad actual. Madrid: Editorial Civitas, S.A., 1995.

ROCHA, Leonel Severo. Epistemologia Jurídica. 2. ed. São Leopoldo: Ed. UNISINOS, 2003.

ROUANET, Sérgio. As razões do Iluminismo. São Paulo: Companhia das Letras, 1998.

SANTOS, Boaventura de Sousa. A crítica da razão indolente - contra o desperdício da experiência. São Paulo: Cortez, 2000.

SANTOS, Moacyr Amaral. Primeiras Linhas de Direito Processual Civil. São Paulo: Saraiva, 2000.

SILVA, Ovídio Araújo Baptista da. Jurisdição e Execução na Tradição Romano-Canônica.Porto Alegre: Revista dos Tribunais, 1998

THEODORO JÚNIOR, Humberto. Curso de Direito Processual Civil. Rio de Janeiro: Forense, 1990.

TORNAGHI, Hélio. Comentários ao Código de Processo Civil. São Paulo: Revista dos Tribunais, 1975, v. I.

TOURAINE, Alain. Crítica da modernidade. Traduzido por Elia Ferreira Edel. 3. ed. Rio de Janeiro: Vozes, 1995.

VATTIMO, Gianni. En torno a la posmodernidad. Santafé de Bogotá: Anthropos, 1994.

VIRILIO, Paul. A Bomba Informática. Traduzido por Luciano V. Machado. São Paulo: Estação Liberdade, 1999. 